\title{
Connected health: in the right place at the right time
}

\author{
Stefano Omboni ${ }^{1,2}$ \\ ${ }^{1}$ Clinical Research Unit, Italian Institute of Telemedicine, Varese 21048, Italy. \\ ${ }^{2}$ Department of Cardiology, Sechenov First Moscow State Medical University, Moscow 119991, Russian Federation.
}

Correspondence to: Prof. Stefano Omboni, Clinical Research Unit, Italian Institute of Telemedicine, Via Colombera 29, Solbiate Arno (Varese) 21048, Italy. E-mail: stefano.omboni@iitelemed.org

How to cite this article: Omboni S. Connected health: in the right place at the right time. Conn Health 2021;1:1-6. http://dx.doi.org/10.20517/ch.2021.01

Received: 10 Feb 2021 Accepted: 13 Feb 2021 Available online: 3 Mar 2021

Academic Editor: Stefano Omboni Copy Editor: Xi-Jun Chen Production Editor: Xi-Jun Chen

\section{INTRODUCTION}

Digital health or electronic health (e-health) involves a broad group of activities that use communication and information technologies to store, retrieve, share, and exchange health-related information for prevention, diagnosis, treatment, monitoring, educational, and administrative purposes ${ }^{[1]}$. Due to the technological progress of recent years, the term, originally indicating activities carried out at the local site, has now been extended to the electronic processes involving the Internet and healthcare delivery over a distance, the so-called telemedicine or telehealth ${ }^{[2]}$. Indeed, telemedicine services are currently the most popular e-health services among healthcare professionals and consumers. A summary of the most typical e-health services available nowadays is reported in Table 1.

\section{CONNECTED HEALTH}

Telemedicine means "healing at a distance", a composite word of the Greek term "tele", meaning "distance", and the Latin term "medicus", meaning "to heal". Telemedicine or "connected health" basically refers to the specific use of information communication technology (ICT) to deliver healthcare, clinical and administrative services, and medical education, remotely from one site to another, to offer more prompt and efficient diagnosis and clinical care ${ }^{[3]}$. Telemedicine services based on the Internet and, more recently, after the introduction of smartphones and tablets, mobile health services (so-called "m-health") are now the most popular and widespread applications in the field of e-health ${ }^{[4]}$. They are commonly used for remote monitoring (telemonitoring) of specific vital and non-vital parameters. According to current models, a web-based shared platform that favors collaborative care and interactions between patients and healthcare operators and among professionals is the most popular and effective telemedicine intervention. The typical

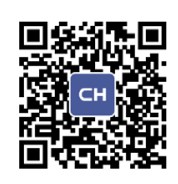


Table 1. Main categories of e-health services that are currently available

\begin{tabular}{|c|c|}
\hline Electronic health record & $\begin{array}{l}\text { A platform used to store a patient's clinical history (test results, medication, disease history) } \\
\text { with the potential for it to be shared online with other providers outside the practice }\end{array}$ \\
\hline $\begin{array}{l}\text { Administrative and patient information } \\
\text { systems }\end{array}$ & $\begin{array}{l}\text { EHR integrated with tools that can be used to support both the administrative and clinical } \\
\text { activities to manage administrative data, appointments, billing, planning, budgeting, and } \\
\text { personnel }\end{array}$ \\
\hline Clinical decision support tools & $\begin{array}{l}\text { Tools that use patient-specific data to present evidence-based guidance to clinicians at } \\
\text { appropriate times throughout the care planning process, guiding and reinforcing decisions at } \\
\text { the point of care and assisting with clinical decision-making tasks }\end{array}$ \\
\hline Web-based technologies and services & $\begin{array}{l}\text { E-learning for patients (interactive education programs on lifestyle, information related to } \\
\text { diseases and treatments) and healthcare professionals (continuing medical education), online } \\
\text { discussion groups for patients and healthcare professionals }\end{array}$ \\
\hline Virtual healthcare & $\begin{array}{l}\text { Digital clinics which enable teleconsultation and videoconferencing, exchange of diagnostic } \\
\text { images, and in some cases, computer-assisted surgery through robotics }\end{array}$ \\
\hline Medical research support technologies & $\begin{array}{l}\text { Based on grid technologies, which allow powerful computing and data management } \\
\text { capabilities to handle large amounts of heterogeneous data }\end{array}$ \\
\hline Medication management services & $\begin{array}{l}\text { Online prescription and drug dispensation, patient's adherence tracking with automatic } \\
\text { feedback to the patient, or case management by a healthcare professional }\end{array}$ \\
\hline Medical imaging & $\begin{array}{l}\text { Storage (for local access) or exchange (for remote access) of diagnostic images or videos (so } \\
\text { called "teleimaging") or pathology slide images ("telepathology"). Data exchange may include } \\
\text { radiograms, CT or MRI-scans, ultrasound videos, fundoscopy images, etc., and may occur in } \\
\text { real-time or after the visit }\end{array}$ \\
\hline Telemedicine, telecare, m-health & $\begin{array}{l}\text { Remote data transmission of various measurements (e.g., BP, heart rate, ECG, body weight, } \\
\text { body temperature, oxygen saturation, peak respiratory flow, blood glucose) and patient's } \\
\text { health status from a patient's home or a professional healthcare setting to the doctor's } \\
\text { practice or the hospital. It also includes televisit and teleconsultation }\end{array}$ \\
\hline
\end{tabular}

EHR: Electronic health record; CT: computed tomography; MRI: magnetic resonance imaging; BP: blood pressure; ECG: electrocardiogram.

provision model shown in Figure 1 follows a "closed-looped" scheme, also called "Internet-of-MedicalThings" (IoMT), namely a connected infrastructure of health systems and services that are designed to detect issues before they become critical and enable early intervention by caregivers ${ }^{[2]}$.

\section{TELEMEDICINE DIFFUSION WORLDWIDE}

Telemedicine is a promising tool for improving access to care and empowering patients, influencing their attitudes and behaviors, and improving the quality of delivered care and patient's health status. The most popular telemedicine applications are in the field of radiology, cardiology, dermatology, and psychiatry. Patients managed with telemedicine are predominantly diagnosed with cardiovascular diseases such as heart failure or hypertension, and metabolic disease, such as diabetes. Recent estimates indicate that seven million patients are managed annually with telemedicine worldwide. Europe and North America are traditional markets for telemedicine ${ }^{[5,6]}$. In the US, there are currently some 200 telemedicine networks with 3500 service sites. More than 50\% of all US Hospitals have adopted some form of connected health for remote patient monitoring. Approximately $80 \%$ of European countries have telemedicine services implemented. Diagnosis is the main reason for resorting to telemedicine applications, followed by emergency care (so-called "telecare") and vital sign monitoring. Asia, in particular China, and Oceania are emergent markets for telemedicine, especially following COVID-19 ${ }^{[6]}$. Although televisit and teleconsultation are the most popular telemedicine solutions, home-based telemonitoring is the fastestgrowing telemedicine application, particularly in the context of a global pandemic.

\section{A TECHNOLOGICAL CHALLENGE THAT CAN TURN INTO A POTENTIAL GAME CHANGER FOR THE HEALTHCARE SYSTEM}

During the recent COVID-19 pandemic caused by SARS-CoV-2, digital health, particularly telemedicine, has thrived and resulted worldwide as an indispensable resource to improve patients' management, not only of those infected by the new coronavirus but mostly of patients with chronic illnesses, isolated at home ${ }^{[7-9]}$. In this sense, a major benefit of e-health is the ability to enable "whole-person" comprehensive care 


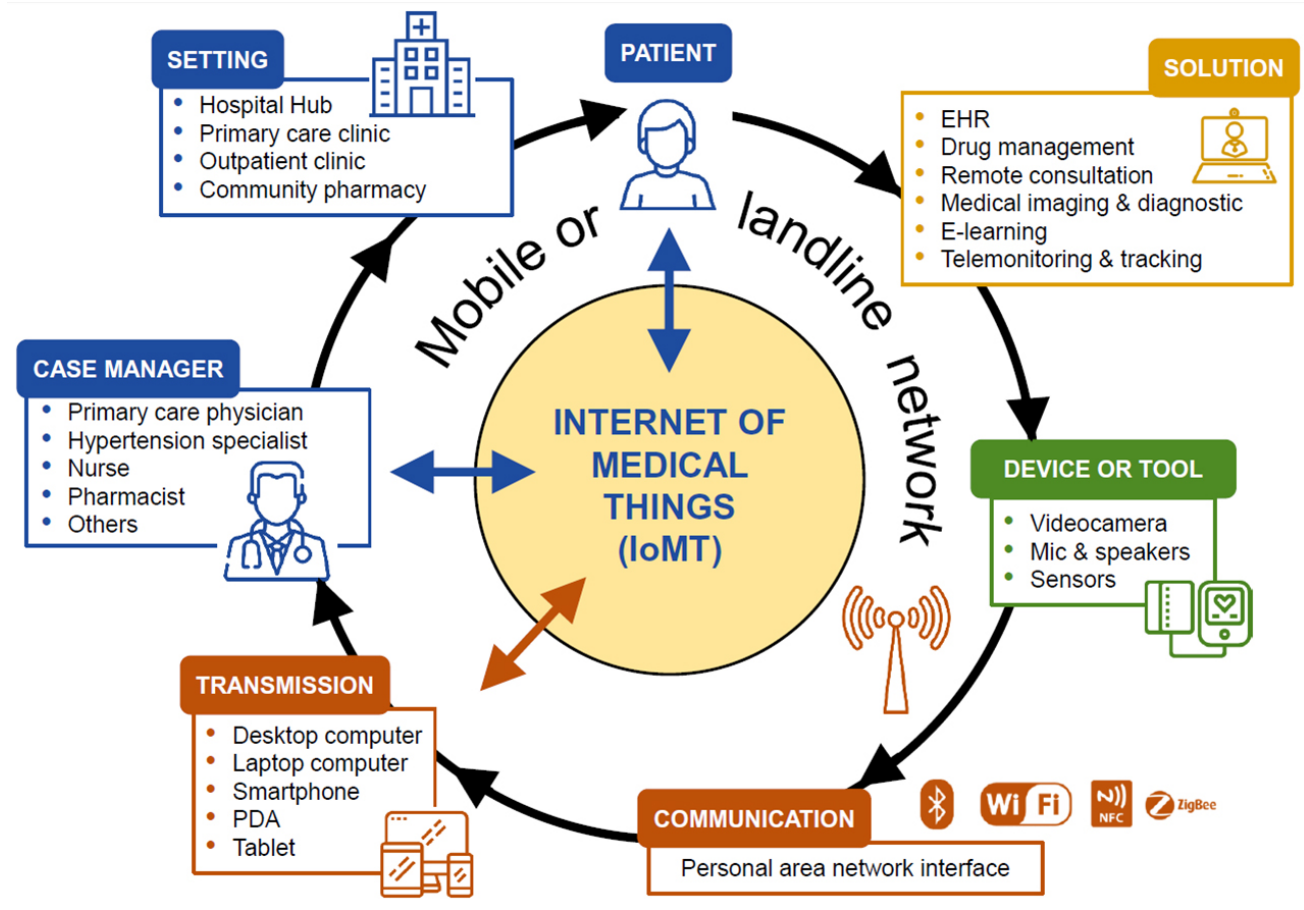

Figure 1. Diagram of most common telemedicine services and their workflow. EHR: Electronic health record; NFC: near filed communication; PDA: personal digital assistant; loMT: Internet of Medical Things. This figure is used with permission from Omboni ${ }^{[2]}$.

according to a personalized patient-centered model of care. According to this model, health information technologies are used to create multidisciplinary networks involving various healthcare professionals (e.g., physician, nurse, and pharmacist) to make the communication among the care team and the patient more efficient, personalizing the care and favorably impacting on patient's health.

Many studies published in the last two decades have shown a high acceptance of digital health technologies and services by both patients and physicians. Approaches based on e-health solutions are particularly suitable for preventing cardiovascular diseases and managing chronic conditions. Other applications include the early diagnosis of dermatological or pneumological diseases. As shown in Table 2, evidence exists of high effectiveness for managing patients with hypertension ${ }^{[10-13]}$, heart failure ${ }^{[12-15]}$, acute myocardial infarction and coronary artery disease ${ }^{[16,17]}$, stroke ${ }^{[18]}$, chronic kidney disease ${ }^{[19]}$, diabetes ${ }^{[12,13,15,20]}$, chronic lung disease ${ }^{[12,13,15]}$, cancer $^{[15]}$, and mental illness ${ }^{[21]}$.

Unfortunately, integrating e-health and telemedicine into the clinical practice is not without challenges due to several technical, infrastructural, economical, regulatory, and cultural barriers, as summarized in Table 3 .

\section{A NEW JOURNAL: CONNECTED HEALTH}

Due to their unequivocal benefit for improving medical care, more and more e-health solutions have been developed and tested in feasibility and clinical studies in recent years. A search of the literature (Medline) for the last three decades based on terms such as "digital health", "digital medicine", "digital care", "eHealth", "mhealth", "telemedicine", "telehealth", and "telecare" returned 115,169 publications. A progressive marked increment in the number of publications has been observed over the years [Figure 2].

Current statistics from SJR Scimago Journal \& Country Rank indicate 83 ranked journals focusing on digital health or bioinformatics ${ }^{[22]}$. The majority of journals have been established in the last two decades [Figure 2]. Only four of these journals have discontinued publications between 2016 and 2018. 
Table 2. Evidence of clinical benefit of e-health and telehealth interventions in various chronic conditions according to main metaanalyses and systematic reviews of randomized controlled studies

\begin{tabular}{|c|c|c|}
\hline Condition & Main clinical benefit & Level of benefit \\
\hline Diabetes $^{[12,13,15,20]}$ & Improved glycemic control in type 2 , but not type 1 patients & +++ \\
\hline Heart failure ${ }^{[12-15]}$ & Reduced mortality and hospital admissions & +++ \\
\hline $\begin{array}{l}\text { Chronic lung disease (e.g., asthma and } \\
\text { chronic obstructive pulmonary disease) }{ }^{[12,13,15]}\end{array}$ & $\begin{array}{l}\text { Improvement in lung function, reduction in the symptoms associated } \\
\text { with the illness, and improvement in perceived quality of life }\end{array}$ & ++ \\
\hline Arterial hypertension ${ }^{[10-13]}$ & Improvement in blood pressure control & ++ \\
\hline Overweight or obesity ${ }^{[13]}$ & Reduction in body weight & ++ \\
\hline Stroke ${ }^{[18]}$ & $\begin{array}{l}\text { Significant improvement in recovery from motor deficits, higher cortical } \\
\text { dysfunction, and depression }\end{array}$ & ++ \\
\hline Chronic kidney disease ${ }^{[19]}$ & $\begin{array}{l}\text { Improvement in the management of dietary sodium intake and fluid } \\
\text { management }\end{array}$ & + \\
\hline Acute myocardial infarction ${ }^{[16]}$ & Reduced in-hospital mortality & $+/-$ \\
\hline $\begin{array}{l}\text { Secondary prevention for patients with } \\
\text { coronary artery disease }\end{array}$ & Improvement in modifiable cardiovascular risk factors & $+/-$ \\
\hline Cancer $^{[15]}$ & Improvement in quality of life & $+/-$ \\
\hline Mental illness ${ }^{[21]}$ & Improvement in adherence to drug treatment & + \\
\hline
\end{tabular}

Table 3. Benefits and barriers to implementation of proper e-health and telehealth interventions

\begin{tabular}{ll}
\hline Benefits & \multicolumn{1}{c}{ Barriers } \\
\hline Improved health outcomes & Long-term efficacy not proven \\
Increased access to care & Interoperability \\
Management of distant patients & Usability \\
Accelerated delivery of care & Infrastructural barriers \\
Increased number of patients served & Lack of reimbursement \\
Time-saving & Regulatory and privacy issues \\
Cost efficiency & Lack of validation and certification \\
Interprofessional cooperation & Digital divide \\
Patient's empowerment & Physicians' inertia \\
\hline
\end{tabular}

Given this picture, do we need another journal publishing articles related to digital health? Surely, we need a virtual place where computer scientists, bioengineers, physicians, and various healthcare professionals, including pharmacists and nurses, can share and discuss their research results in a pragmatic way, focusing on their discoveries' practical applications. We need a multidisciplinary "agora" where topical experts can exchange ideas and opinions and present innovative digital health solutions that can help boost the integration of e-health services and telemedicine in the armamentarium of healthcare services available to healthcare professionals and patients in the clinical practice.

In this light, the scope of the new journal "Connected Health" is to gather high-quality original research or review papers presenting the available evidence on new digital health technologies, their clinical usefulness, and applications for managing acute and chronic patients. The journal is divided into different sections dedicated to the various aspects of digital health applications for disease management. Notably, the following topics are relevant:

- Innovations in technologies and diagnostics: Technical papers related to m-health, e-health, and telehealth applications, wearable sensors, artificial intelligence, machine learning, blockchain, robotic care (telesurgery), smart home, virtual reality, etc.

- Clinical aspects: Feasibility and usability studies, efficacy studies (including the long-term effect on major health status indices, quality of life, performance status, medication adherence, etc.).

- Economic studies: Cost-effectiveness of digital solutions.

- Policy: Regulatory issues, health policies, ethics, privacy, and legal issues.

- Personalized and precision medicine: How digital health can provide "whole-person" individualized management of patients, moving disease management to a personalized patient-centered model of care.

- Telepharmacy: Medication dispensation, pharmacovigilance, monitoring of medication adherence and patients' health status, and acting as point-of-care under the supervision of physicians. 

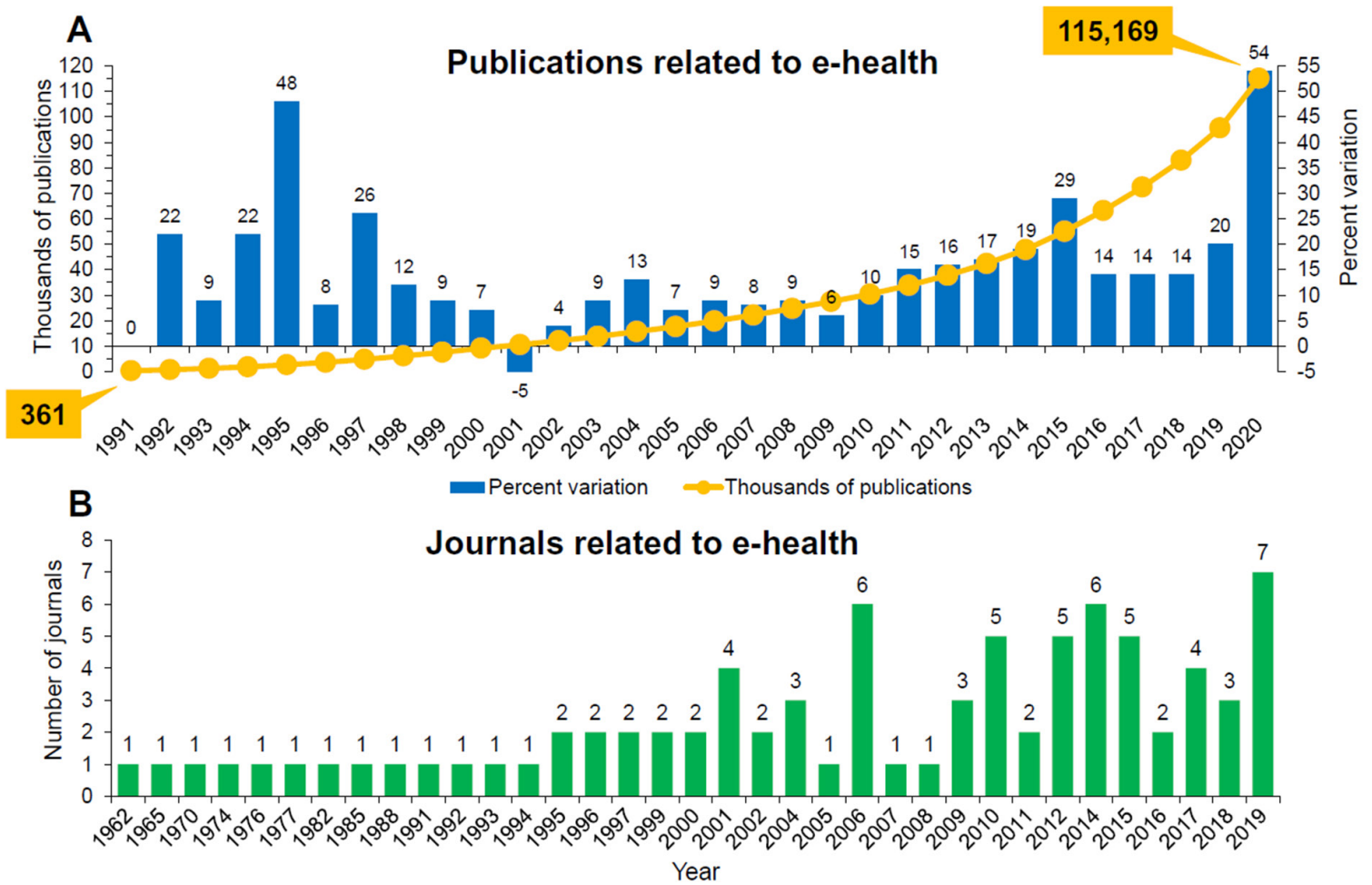

Figure 2. The number of papers related to e-health published in the last 30 years. The line refers to the cumulative number of publications, while the bars correspond to the percent variation in the number of publications from year to year (A). The number of journals related to e-health according to their year of foundation (B).

\section{CONCLUSION}

Digital health and telemedicine are great challenges for any healthcare system worldwide. The current COVID-19 pandemic has finally made stakeholders and politicians aware that remote managing of infected people and patients with chronic conditions may increase access to care and its effectiveness, and it is timeand cost-saving. It also lowers the amount of strain on healthcare workers, who are striving to manage patients in hospitals and emergency rooms. As claimed in the Editorial title, the new journal Connected Health is coming in the right place (the Internet, where digital health is mostly deployed) and at the right time (when the coronavirus outbreak has demanded digital health solutions to improve patients' management and outcomes).

\section{DECLARATIONS}

\section{Authors' contributions}

The author contributed solely to the article.

\section{Availability of data and materials}

Not applicable.

Financial support and sponsorship

None.

\section{Conflicts of interest}

The author is a scientific consultant of Biotechmed Ltd, a provider of telemedicine services.

\section{Ethical approval and consent to participate}

Not applicable. 


\section{Consent for publication}

Not applicable.

\section{Copyright}

(c) The Author(s) 2021.

\section{REFERENCES}

1. Moghaddasi H, Asadi F, Hosseini A, Ebnehoseini Z. E-Health: a global approach with extensive semantic variation. $J$ Med Syst 2012;36:3173-6

2. Omboni S. Connected Health in Hypertension Management. Front Cardiovasc Med 2019;6:76.

3. Sood S, Mbarika V, Jugoo S, et al. What is telemedicine? A collection of 104 peer-reviewed perspectives and theoretical underpinnings. Telemed J E Health 2007;13:573-90.

4. Silva BM, Rodrigues JJ, de la Torre Díez I, López-Coronado M, Saleem K. Mobile-health: A review of current state in 2015. J Biomed Inform 2015;56:265-72.

5. Intelligence M. Europe telemedicine market - growth, trends, and forecasts (2021 - 2026). Available from: https://www. mordorintelligence.com/industry-reports/european-telemedicine-market-industry. [Last accessed on 26 Feb 2021]

6. Intelligence M. Telemedicine market - growth, trends, COVID-19 impact, and forecasts (2021 - 2026) Available from: https://www. mordorintelligence.com/industry-reports/global-telemedicine-market-industry. [Last accessed on 26 Feb 2021]

7. Smith AC, Thomas E, Snoswell CL, et al. Telehealth for global emergencies: Implications for coronavirus disease 2019 (COVID-19). $J$ Telemed Telecare 2020;26:309-13.

8. Hollander JE, Carr BG. Virtually Perfect? Telemedicine for Covid-19. N Engl J Med 2020;382:1679-81.

9. Monaghesh E, Hajizadeh A. The role of telehealth during COVID-19 outbreak: a systematic review based on current evidence. BMC Public Health 2020;20:1193.

10. Omboni S, Campolo L, Panzeri E. Telehealth in chronic disease management and the role of the Internet-of-Medical-Things: the Tholomeus ${ }^{\circledR}$ experience. Expert Rev Med Devices 2020;17:659-70.

11. Omboni S, McManus RJ, Bosworth HB, et al. Evidence and recommendations on the use of telemedicine for the management of arterial hypertension: an international expert position paper. Hypertension 2020;76:1368-83.

12. Paré G, Moqadem K, Pineau G, St-Hilaire C. Clinical effects of home telemonitoring in the context of diabetes, asthma, heart failure and hypertension: a systematic review. J Med Internet Res 2010;12:e21.

13. Marcolino MS, Oliveira JAQ, D’Agostino M, Ribeiro AL, Alkmim MBM, Novillo-Ortiz D. The impact of mHealth interventions: systematic review of systematic reviews. JMIR Mhealth Uhealth 2018;6:e23.

14. Kitsiou S, Paré G, Jaana M. Effects of home telemonitoring interventions on patients with chronic heart failure: an overview of systematic reviews. J Med Internet Res 2015;17:e63.

15. Hanlon P, Daines L, Campbell C, McKinstry B, Weller D, Pinnock H. Telehealth interventions to support self-management of long-term conditions: a systematic metareview of diabetes, heart failure, asthma, chronic obstructive pulmonary disease, and cancer. $J$ Med Internet Res 2017;19:e172.

16. de Waure C, Cadeddu C, Gualano MR, Ricciardi W. Telemedicine for the reduction of myocardial infarction mortality: a systematic review and a meta-analysis of published studies. Telemed J E Health 2012;18:323-8.

17. Brørs G, Pettersen TR, Hansen TB, et al. Modes of e-Health delivery in secondary prevention programmes for patients with coronary artery disease: a systematic review. BMC Health Serv Res 2019;19:364.

18. Sarfo FS, Ulasavets U, Opare-Sem OK, Ovbiagele B. Tele-rehabilitation after stroke: an updated systematic review of the literature. $J$ Stroke Cerebrovasc Dis 2018;27:2306-18.

19. Stevenson JK, Campbell ZC, Webster AC, et al. eHealth interventions for people with chronic kidney disease. Cochrane Database Syst Rev 2019;8:Cd012379.

20. Lee PA, Greenfield G, Pappas Y. The impact of telehealth remote patient monitoring on glycemic control in type 2 diabetes: a systematic review and meta-analysis of systematic reviews of randomised controlled trials. BMC Health Serv Res 2018;18:495.

21. Basit SA, Mathews N, Kunik ME. Telemedicine interventions for medication adherence in mental illness: A systematic review. Gen Hosp Psychiatry 2020;62:28-36.

22. Lab S. Scimago Journal \& Country Rank (SJR). Available from: https://www.scimagojr.com/. [Last accessed on 26 Feb 2021] 